\section{Hans Rooseboom}

De schaduw van de fotograaf. Positie en status van een nieuw beroep 1839-1889

Leiden (Primavera Pers) 2008, 400 p., ill., $€ 34,50$, ISBN 9789059970526

De foto op het omslag, van de schaduw van een fotograaf met statief, is symbolisch voor het feit dat zo ongelooflijk weinig kennis beschikbaar is over de eerste pioniers op het gebied van de fotografie in Nederland. Wie waren de fotografen? Wie waren hun klanten?

De auteur van de studie, Hans Rooseboom, schetst in deze handelseditie van zijn proefschrift de vroege fotografie als een onbeduidend verschijnsel, temidden van de grote uitvindingen van de negentiende eeuw. Fotografie was een gebruiksvoorwerp, het beroep fotograaf simpel en ambachtelijk. Het negentiendeeeuwse fotoatelier was een kleinschalig bedrijf, met een beperkte distributie; oplagen waren niet hoog. De professie was nieuw, fotografen moesten zich een positie zien te veroveren. Pas rond I 860 ontstond een beroepsgroep van enige omvang.

Beroepsfotografen waren portretfotografen. Het was de periode van de 'inburgering' van de fotografie. Het populairste onderwerp in de periode I839-I889 was het portret, op gestandaardiseerd formaat. Miljoenen exemplaren zijn in familiekringen bewaard gebleven, op cartes-de-visite en in albums. De populariteit van een ruilcultuur met cartes-de-visites was groot. Diepgravend en langdurig onderzoek van de auteur, vooral gebaseerd op (auto)biografieën van literatoren en wetenschappers, leidde, zoals hij zelf meermalen aangeeft, lang niet altijd tot het gewenste resultaat. In saillante details en aan de hand van veel citaten reconstrueert Rooseboom de poseersessies van bekende Nederlanders, zoals Multatuli.

Bronnen zijn schaars. Kiezerslijsten, kasboekjes en belastinggegevens geven weinig inzicht in de verdeling van de welvaart onder belastingplichtige fotografen. Ook aan belangenbehartiging en beroepsorganisaties van fotografen ontbrak het in de negentiende eeuw. De maatschappelijke relevantie van de fotogra- fie blijft buiten beeld in dit onderzoek, want een verworvenheid van de twintigste eeuw.

Rooseboom concludeert, terecht, dat fotografie de kop van jut was, gemeten naar de maatstaven van de beeldende kunst in de tweede helft van de negentiende eeuw. Bovendien was het een schimmige beroepsgroep die weinig sporen naliet: geen brieven, geen administratie, geen negatieven. Zelfs geen enkele interieuropname van een Nederlands fotoatelier. En als het immense fotoarchief van een fotograaf al achterbleef, dan was het ongeïnventariseerd. Dankzij hun klanten, opdrachtgevers, en niet te vergeten de ambtenaren van de overheid, weten we iets meer.

Hans Rooseboom (1966) is sinds I99I conservator fotografie van het Rijksmuseum in Amsterdam. Naast deze deeltijdfunctie heeft Rooseboom op freelance basis gewerkt voor onder meer de RKD en het Nationaal Archief. Met collega Mattie Boom schreef hij het naslagwerk Een nieuwe kunst. Fotografie in de 19de eeuw. De Nationale Fotocollectie in het Rijksmuseum, Amsterdam (I996). Als buitenpromovendus heeft Rooseboom ruim tien jaar aan dit onderzoek gewerkt.

De tekst is zonder meer helder geschreven, hoewel Rooseboom zich soms wat al te populair uitdrukt, zoals in dit geval: 'Multatuli's getob met fotografen'. Maar dat het onderzoek allerminst systematisch van opzet is en een centrale onderzoeksvraag ontbreekt, is een groot manco. Verder slaagt de auteur er niet altijd in boven de materie te gaan staan, informatie te clusteren en conclusies te trekken die gelden voor de collectieve beroepsgroep. Daarbij komt dat de contextualisering van het onderwerp niet verder reikt dan de periode van onderzoek.

Onbeantwoord blijven vragen als: hoe zet de professionalisering van fotografen zich door na I889? Bevonden fotografen zich in een gunstige marktpositie en hoe hebben fotografen het beroepsperspectief kunnen verbeteren ${ }^{\text {II }} \mathrm{De}$ geschiedschrijving van de negentiende-eeuwse fotografie in Nederland is monografisch georienteerd, constateert Rooseboom (wat overigens ook grotendeels geldt voor die van de twintigste eeuw). Reeds in zijn inleiding doet hij aanbeve- 
lingen voor verder onderzoek: meer biografieën van negentiende-eeuwse Amsterdamse fotografen en hun verdiensten in een breder cultuurhistorisch perspectief plaatsen.

Welke onderwerpen gingen eigenlijk de hele beroepsgroep aan? Een eerste fotohistorische studie van Ingeborg Leijerzapf uit 1979, een essay van Mariette Haveman, getiteld Over fotografen, verschenen in I992 en de prelude van het onderhavige proefschrift in het standaardwerk Dutch Eyes (2007) raakten aan deze thematiek.

Wat was nu de maatschappelijke positie en status van de gemiddelde fotograaf? Het proefschrift voorziet in die zin niet in een lacune; het is geen overzicht van negentiende-eeuwse Nederlandse fotografie in al haar aspecten, daarvoor zijn de bronnen te spaarzaam. De geraadpleegde documenten, die vaak betrekking hebben op één persoon, zijn niet representatief voor de hele - nieuwe - beroepsgroep. Veel aandacht gaat uit naar het prestige van het beroep fotograaf, naar de sociaal-economische positie van fotografen, naar beroepenstratificatie.

Een gehanteerde - ongebruikelijke - methode van onderzoek, die wellicht bijdraagt aan de emancipatie van de fotografiewetenschap, is het analyseren en synthetiseren van archivalische bronnen uit gemeentearchieven (onder meer huwelijksakten, kohieren van rijksbelastingen, bouwtekeningen en boedelinventarissen). Deze verschaften de auteur enig inzicht in de inkomsten, klantenkring, beroepscultuur, status, werkmethode, vakopvatting en vooral de wankele maatschappelijke positie van deze beroepsbeoefenaar. In acht hoofdstukken worden deze aspecten van de beroepsgroep achtereenvolgens besproken.

Heeft fotografie de schilderkunst concurrentie aangedaan, en zo ja, in welke mate? Deze interessante deelvraag is de crux van dit onderzoek. De uitvinding van de daguerreotypie heeft de schilderkunst niet overbodig gemaakt. Die mythe was al doorbroken, maar de auteur draagt enkele argumenten aan die nieuw inzicht bieden in de processen van professionalisering van fotografen in Nederland in de negentiende eeuw: het aantal schilders liep niet terug, foto- portretten waren niet artistiek, hadden geen grandeur en getuigden van een overmaat aan realisme.

Sterker nog, en dat is de belangrijkste vinding van Rooseboom: fotografie heeft de verspreiding van de schilderkunst helpen vergroten. Hij sluit daarmee aan bij het promotieonderzoek van Robert Verhooft uit 2004 over de vermenigvuldiging van beelden in prentkunst en fotografie. De toepassing van fotografie onder schilders als reproductietechniek en voor studiedoeleinden was opmerkelijk groot. De publicatie sluit af met een uitgebreide literatuurverwijzing en een zeer beknopte verklarende lijst met fotografische termen. Met een index op naam, het uitgebreide notenapparaat en een lijstje van gebruikte afkortingen beslaat het nawerk honderd pagina's: een kwart van het boek. $^{2}$

\section{Noten}

I Zie voor de mate waarin en de manier waarop het beroep collectief geprofessionaliseerd is in de tweede helft van de twintigste eeuw en voor een beschrijving van de beroepsomstandigheden van zelfstandig gevestigde fotografen: B. Hofstede, Fotografie als beroep. Over de professionalisering van fotografie als artistiek beroep, Rotterdam (doctoraalscriptie EU) I99I; B. Hofstede, 'Dilemma's van fotografen. Professionalisering en autonomie', in: H. Van Dulken (red.), Stilstaande beelden. Ondergang en opkomst van de fotografie (Kunst en beleid in Nederland 7), Amsterdam I995, p. 55-79; M. Thijsen, Het bedriifsfotoboek 1945-1965. Professionalisering van fotografen in Nederland, Rotterdam 2002.

2 Toch even een blik vooruit werpen: ruim een eeuw later neemt de commercialisering en technologisering van het medium een vlucht. De globale beeldcultuur doet zijn intrede. Een schimmige beroepsgroep heeft dan allang plaats gemaakt voor een 'overgeprofessionaliseerde wereld' in de eenentwintigste eeuw, waarin de amateurfotografie zelfs tot een kunststrategie kan uitgroeien zoals Jorinde Seijdel beschrijft in het artikel 'N JOY POV RTY' in de nieuwsbrief van het Stedelijk Museum Bureau Amsterdam (sm BA).

Mirelle Thijsen 